\title{
Selecting a BRCA risk assessment model for use in a familial cancer clinic
}

\author{
Seema M Panchal ${ }^{1,2}$, Marguerite Ennis ${ }^{3}$, Sandra Canon ${ }^{1}$ and \\ Louise J Bordeleau*1,2
}

\begin{abstract}
Address: ${ }^{1}$ Mount Sinai Hospital, Marvelle Koffler Breast Centre, Toronto, Ontario, Canada, ${ }^{2}$ The University of Toronto, Faculty of Medicine,

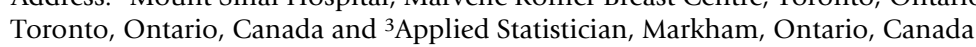

Email: Seema M Panchal - spanchal@mtsinai.on.ca; Marguerite Ennis - m.ennis@utoronto.ca; Sandra Canon - scanon@mtsinai.on.ca; Louise J Bordeleau* - lbordeleau@mtsinai.on.ca

* Corresponding author
\end{abstract}

Published: 22 December 2008

BMC Medical Genetics 2008, 9:116 doi:10.1 186/147|-2350-9-1/6

This article is available from: http://www.biomedcentral.com/I47I-2350/9/1 I6

(C) 2008 Panchal et al; licensee BioMed Central Ltd.

This is an Open Access article distributed under the terms of the Creative Commons Attribution License (http://creativecommons.org/licenses/by/2.0), which permits unrestricted use, distribution, and reproduction in any medium, provided the original work is properly cited.

Received: 17 April 2008

Accepted: 22 December 2008

\begin{abstract}
Background: Risk models are used to calculate the likelihood of carrying a BRCAI or BRCA2 mutation. We evaluated the performances of currently-used risk models among patients from a large familial program using the criteria of high sensitivity, simple data collection and entry and BRCA score reporting.
\end{abstract}

Methods: Risk calculations were performed by applying the BRCAPRO, Manchester, Penn II, Myriad II, FHAT, IBIS and BOADICEA models to 200 non-BRCA carriers and 100 BRCA carriers, consecutively tested between August 1995 and March 2006. Areas under the receiver operating characteristic curves (AUCs) were determined and sensitivity and specificity were calculated at the conventional testing thresholds. In addition, subset analyses were performed for low and high risk probands.

Results: The BRCAPRO, Penn II, Myriad II, FHAT and BOADICEA models all have similar AUCs of approximately 0.75 for BRCA status. The Manchester and IBIS models have lower AUCs (0. and 0.47 respectively). At the conventional testing thresholds, the sensitivities and specificities for a BRCA mutation were, respectively, as follows: $\operatorname{BRCAPRO}(0.75,0.62)$, Manchester $(0.58,0.7 \mathrm{I})$, Penn II $(0.93,0.3 \mathrm{I})$, Myriad II $(0.7 \mathrm{I}, 0.63)$, FHAT $(0.70,0.63)$, IBIS $(0.20,0.74)$, BOADICEA $(0.70,0.65)$.

Conclusion: The Penn II model most closely met the criteria we established and this supports the use of this model for identifying individuals appropriate for genetic testing at our facility. These data are applicable to other familial clinics provided that variations in sample populations are taken into consideration.

\section{Background}

Breast cancer is the most frequently diagnosed cancer among women in North America. Statistics for the year 2007 showed that 1 in 9 women will be diagnosed with the disease and 1 in 27 women will die of it [1]. Although the specific etiology of breast cancer is unknown, hormonal, reproductive and hereditary factors have all been shown to be risk factors. 
Among the hereditary factors involved in breast cancer, single gene mutations contribute a significant increase in risk. In 1990, the BRCA1 gene was mapped to chromosome 17 by genetic linkage analysis [2], and the BRCA2 gene was subsequently identified and mapped to chromosome 13 [3]. Population-based studies have shown that mutations in BRCA1 and BRCA2 confer an increased risk of breast, ovarian and other cancers. The syndrome associated with BRCA mutations is termed Hereditary Breast and Ovarian Cancer (HBOC). Most breast cancers known to be hereditary are attributable to HBOC. Other syndromes such as Li-Fraumeni syndrome [4], PTEN mutation-associated syndromes [5] and heterozygous Ataxia Telangiectasia [6] account for less than 5\% of hereditary breast cancers.

Cancer risks associated with BRCA1 and BRCA2 mutations have been well documented, but are varied. These risks probably depend on family history, the population under study and the mutation type [7]. Most recent risk estimates from a large United States sample suggest that breast cancer risks up to age 70 for BRCA1 and BRCA2 mutation carriers are $43 \%$ and $46 \%$ respectively, and ovarian cancer risks are $39 \%$ and $22 \%$ respectively [8]. However, there are discrepancies in risk estimates, as previous studies have shown breast cancer risks of 56-87\% [9] and ovarian cancer risks of 10-40\% [10]. Also, there may be increased risks of other cancers such as male breast cancer [11], melanoma, pancreas and prostate cancer associated with BRCA mutations [12].

Various methodologies have been developed to identify mutations in BRCA1 and BRCA2, and numerous studies have been performed to evaluate the benefits and limitations of each method. In the United States, testing is commonly performed by gene sequencing and large deletion and rearrangement screening [13]. In other areas of the world, denaturing high performance liquid chromatography (DHPLC) is the method used for detecting mutations [14]. In Ontario, Canada, the testing methodology changed in 2007 from protein truncation testing (PTT) with sequencing of exons 2 and 5 of BRCA1, to the currently-used DHPLC and multiplex ligation-dependent probe assay (MLPA) [15,16].

Individuals with known BRCA mutations are managed differently from the general population. Mutation carriers are offered intensified surveillance for early detection, chemoprevention and risk-reducing surgeries. Knowledge of a hereditary predisposition can significantly alter medical management and follow-up for carriers, regardless of previous cancer history [17], and may allow access to healthcare resources not widely available to individuals at general population risk.
Patients gain access to BRCA testing through familial cancer genetics programs. Health care providers refer patients to these programs because of a family history of cancer. Given that funding for genetic testing is limited and that $B R C A$ mutations are rare even in the referred population, the challenge remains to identify those individuals most likely to carry a mutation prior to offering genetic testing. A family history assessment is crucial for this process. This can involve a review of a detailed three-generation pedigree by a specialist, and also a risk calculation using validated risk assessment models.

The BRCAPRO [18-20], Myriad II [21], Couch (also known as Penn) [22], Family History Assessment Tool (FHAT) [23], Manchester [24], Penn II [25], IBIS [26], and Breast and Ovarian Analysis of Disease Incidence and Carrier Estimation Algorithm (BOADICEA) [27,28] models have all been developed to predict the probability of identifying germline BRCA mutations in an individual or a family. BRCAPRO, Myriad II, Couch and FHAT were among the first risk models developed and have been in clinical use for a number of years through CaGene software. The Manchester, Penn II, IBIS and BOADICEA models were developed more recently. Each model calculates risk on the basis of the inclusion of different cancer diagnoses within a family. All models incorporate a family history of breast and ovarian cancer. In addition, the FHAT includes colon and prostate cancer, while the Manchester, BOADICEA and Penn II models include prostate and pancreatic cancer. The IBIS model only includes female diagnoses of breast and ovarian cancer (Table 1).

Although BRCA testing in Ontario, Canada is often based on guidelines developed by the Ministry of Health and Long-Term Care (MOHLTC), risk assessments prove useful when eligibility is not clear. This study was planned to evaluate all the available risk assessment models in order to identify the model or models that will be of most benefit in our population. We established the following criteria for assessing the models. The most appropriate model should have:-

1. At least $90 \%$ sensitivity to capture as many BRCA mutation carriers as possible. To establish high sensitivity, a lower specificity is acceptable because the test carries few negative consequences.

2. Applicability to as many probands as possible regardless of cancer status, sex or degree of cancer history in the family.

3. A tendency towards easy and efficient data collection and entry. 
Table I: Applicability and ease of use of risk assessment models.

\begin{tabular}{|c|c|c|c|c|c|}
\hline & $\begin{array}{l}\text { Calculation } \\
\text { method }\end{array}$ & Cancers included & Inclusiveness & $\begin{array}{l}\text { Family history } \\
\text { required }\end{array}$ & Data entry \\
\hline BRCAPRO & CaGene 4.3 software & $\begin{array}{l}\text { Male and female } \\
\text { breast and ovarian } \\
\text { cancer }\end{array}$ & All individuals & $\begin{array}{l}\left.\right|^{\text {st }} \text { and } 2^{\text {nd }} \text { degree } \\
\text { relatives }\end{array}$ & $\begin{array}{l}\text { Complete pedigree } \\
\text { data entered for } \\
\text { affected and } \\
\text { unaffected }\end{array}$ \\
\hline Myriad II & CaGene 4.3 software & $\begin{array}{l}\text { Male and female } \\
\text { breast and ovarian } \\
\text { cancer }\end{array}$ & All individuals & $\begin{array}{l}\left.\right|^{\text {st }} \text { and } 2^{\text {nd }} \text { degree } \\
\text { relatives }\end{array}$ & $\begin{array}{c}\text { Data searchable by } \\
\text { established tables or } \\
\text { data entry on CaGene } \\
4.3 \text { software }\end{array}$ \\
\hline Couch & CaGene 4.3 software & $\begin{array}{l}\text { Male and female } \\
\text { breast and ovarian } \\
\text { cancer }\end{array}$ & $\begin{array}{l}\text { Excludes probands } \\
\text { from families with } \\
\text { only ovarian or male } \\
\text { breast cancer }\end{array}$ & $\begin{array}{l}1^{\text {st }} \text { and } 2^{\text {nd }} \text { degree } \\
\text { relatives }\end{array}$ & $\begin{array}{c}\text { Data searchable by } \\
\text { established table or } \\
\text { data entry on } \mathrm{CaGene} \\
4.3 \text { software }\end{array}$ \\
\hline $\begin{array}{l}\text { Ontario Family } \\
\text { History } \\
\text { Assessment Tool } \\
\text { (FHAT) }\end{array}$ & CaGene 4.3 software & $\begin{array}{l}\text { Male and female } \\
\text { breast, ovarian, colon } \\
(<50 \text { yrs }) \text {, prostate } \\
\text { cancer }(<50 \text { yrs })\end{array}$ & All individuals & $\begin{array}{l}\left.\right|^{\text {st }} \text { and } 2^{\text {nd }} \text { degree } \\
\text { relatives }\end{array}$ & $\begin{array}{c}\text { Data searchable by } \\
\text { established table or } \\
\text { data entry on } \mathrm{CaGene} \\
4.3 \text { software }\end{array}$ \\
\hline Manchester & Hand calculations & $\begin{array}{l}\text { Male and female } \\
\text { breast, ovarian, } \\
\text { prostate and } \\
\text { pancreatic cancer }\end{array}$ & $\begin{array}{l}\text { Excludes Ashkenazi } \\
\text { Jewish }\end{array}$ & $\begin{array}{c}\text { | st, } 2^{\text {nd }}, \text { and } 3^{\text {rd }} \text { degree } \\
\text { relatives }\end{array}$ & Scoring system \\
\hline Penn II & Web-based & $\begin{array}{l}\text { Male and female } \\
\text { breast, ovarian, } \\
\text { prostate and } \\
\text { pancreatic cancer }\end{array}$ & $\begin{array}{l}\text { Excludes probands } \\
\text { from families with no } \\
\text { breast cancer cases }\end{array}$ & $\begin{array}{c}\text { Ist, } 2^{\text {nd }}, \text { and } 3^{\text {rd }} \text { degree } \\
\text { relatives }\end{array}$ & $\begin{array}{c}\text { One page } \\
\text { questionnaire }\end{array}$ \\
\hline IBIS & $\begin{array}{l}\text { Down-loadable } \\
\text { software }\end{array}$ & $\begin{array}{l}\text { Female breast and } \\
\text { ovarian cancer }\end{array}$ & $\begin{array}{c}\text { Includes only females } \\
\text { unaffected by breast } \\
\text { cancer }\end{array}$ & $\begin{array}{c}\text { Ist, } 2^{\text {nd }}, \text { and } 3^{\text {rd }} \text { degree } \\
\text { relatives }\end{array}$ & $\begin{array}{c}\text { One page } \\
\text { questionnaire }\end{array}$ \\
\hline BOADICEA & Web-based & $\begin{array}{l}\text { Breast, ovarian, } \\
\text { prostate and } \\
\text { pancreatic cancer }\end{array}$ & All individuals & $\begin{array}{c}\left.\right|^{\text {st }}, 2^{\text {nd }}, \text { and } 3^{\text {rd }} \text { degree } \\
\text { relatives }\end{array}$ & $\begin{array}{l}\text { Complete pedigree } \\
\text { data entered for } \\
\text { affected and } \\
\text { unaffected }\end{array}$ \\
\hline
\end{tabular}

4. Overall $B R C A$ risk scores as well as individual BRCA1 and $B R C A 2$ risk scores, because in Canada, genetic testing for both these genes is conducted simultaneously rather than sequentially.

\section{Methods}

The area under the receiver operating characteristic (ROC) curve was selected as the main summary of each model's ability to discriminate between patients with and without a mutation. To obtain an adequate sample size, a retrospective case-control design was utilized. Sample size calculations using PASS 2002 [29] demonstrated that 100 carriers and 200 non-carriers provided estimates of the area under the ROC curve with confidence interval halfwidths of 0.06 to 0.07 over a range of possible true areas, and that increasing the sample size provided little additional benefit. The term 'carriers' is used to describe BRCA1 or BRCA2 mutation carriers, and the term 'noncarriers' is used to describe individuals who have no mutation in BRCA1 or BRCA2.

The Familial Breast Cancer Clinic at Mount Sinai Hospital in Toronto (Canada) receives referrals of probands due to a family history of breast and/or other cancers, or because of a concern about breast cancer risk. Referrals originate from oncologists, surgeons, general practitioners, gynecologists and other healthcare specialists. Referred individuals complete a family history questionnaire prior to their first visit to the clinic. A three generation pedigree is constructed using this questionnaire and a personal interview with a genetic counsellor or nurse practitioner. Where applicable, medical records are obtained to verify cancer diagnoses. Subjects' eligibility for genetic testing is determined on the basis of the MOHLTC testing criteria (Table 2). Informed consent for genetic testing is obtained following a session with a genetic counsellor or a medical geneticist.

\section{Genetic testing}

During the study period, genetic testing was performed in the Molecular Genetics Laboratory of Mount Sinai Hospital in Toronto, Canada using PTT of BRCA1 and BRCA2 combined with DNA sequencing of exons 2 and 5 in $B R C A 1$. DNA and RNA were extracted from whole blood samples and amplified with primers containing linkers to enable the translation of DNA into proteins. PCR products were converted into proteins by the T7 TNT kit. The proteins were separated by size on SDS-PAGE gels for 
Table 2: Ontario Ministry of Health and Long-Term Care (MOHLTC) criteria for BRCAI and BRCA2 genetic testing eligibility

\begin{tabular}{ll}
\hline Non-Ashkenazi Jewish & Ashkenazi Jewish \\
\hline - Breast cancer $<35$ years & - Breast cancer $<50$ years \\
- Male breast cancer & - Breast cancer at any age with family history \\
- Serous ovarian cancer & - Unaffected individual with family history \\
- Breast cancer $<60$ years and family history of ovarian or male breast cancer & \\
- Breast and ovarian cancer in same individual & \\
- Bilateral breast cancer & \\
- 2 cases breast cancer $<50$ years & \\
- 2 cases ovarian cancer & \\
- Known mutation & \\
- Clinical judgment & \\
\hline
\end{tabular}

comparison. Mutation identification was verified using DNA sequencing.

Heteroduplex analysis is used for individuals who qualify for the Ashkenazi Jewish (AJ) screen by MOHLTC criteria. Mutations tested for are 185delAG, 188del11 and 5382insC mutations in BRCA1, and 6174delT in BRCA2.

\section{Patient population and risk assessment}

In May 2006 a chart review of probands who had completed genetic testing in our clinic was conducted. A proband is defined as the index case in the family who serves as a starting point for the study of a pedigree or family history. Probands with prior BRCA1 and BRCA2 genetic testing and known results were included. Probands who had a known relative with a BRCA1 or BRCA2 mutation were excluded. Chart access was approved by the hospital Research Ethics Board (REB). Two hundred non-carriers, consecutively tested between October 2001 and March 2006, and 100 carriers, consecutively tested between August 1995 and March 2006, were identified.

During the chart review, risk assessments were performed on all 300 probands using the three generation pedigrees obtained prior to genetic testing. BRCAPRO, Myriad II, Couch and FHAT were calculated using CaGene 4.3 software [30]. Penn II scores were calculated using the Penn II official public web site http://www.afcri.upenn.edu/itacc/ penn2/[25]. The 2007 updated version of this risk assessment software was used in the analysis. The BOADICEA risks were calculated on-line https://pluto.srl.cam.ac.uk/ cgi-bin/bd1/v1/bd.cgi accessing the most recently available version. Values for unknown ages and unknown year at death were estimated by assuming 25 years between each generation [31]. The updated Manchester model was calculated by hand. Scores for unaffected probands were calculated using a variant form of this model by obtaining scores for the closest affected relative and using Mendelian principles based on degree of relatedness to the proband [24]. IBIS scores were obtained using downloadable soft- ware. Where the models provided separate BRCA1 and $B R C A 2$ scores, the scores were added to obtain a total BRCA score.

The ROC curve was found empirically by calculating sensitivity versus the false positive rate $(1-$ specificity $)$ for each possible threshold value, and the area under the ROC curve (AUC) was obtained using the trapezoidal rule [32]. Ninety-five percent confidence intervals (CI) for the AUCs were calculated using the BCa bootstrap method [33] with 1000 bootstrap samples. For interpretation purposes, note that an AUC of 0.5 is reached by chance alone while 1 is the maximum. The higher the AUC, the higher the model's discriminative power.

We calculated empirical estimates of the sensitivity and specificity for positive BRCA status at the conventional testing thresholds; 10 was used as threshold for all models except the Manchester for which a threshold of 15 has been suggested [24]. In accordance with our criterion of obtaining a model with high degrees of sensitivity, the testing threshold at which each model reached $90 \%$ sensitivity was used and the corresponding specificity was calculated.

To address the problem of selection and spectrum bias, we repeated the above calculations separately for low and high risk probands. Low risk probands were defined as individuals with no first degree relatives with breast or ovarian cancer, and high risk probands as individuals with one or more first degree relatives with breast or ovarian cancer. The AUC was also calculated separately for probands who were and were not of Ashkenazi Jewish descent. The IBIS model, applicable only to unaffected probands, was not used in the subset analyses because the sample size was too small.

\section{Results}

\section{Spectrum of patients studied}

Patient characteristics for the case-control sample of 100 carriers and 200 non-carriers are given in Table 3. Approx- 
imately $35 \%$ of patients in both groups (35 carriers and 71 non-carriers) were in the low risk subset as previously defined. Approximately $40 \%$ of probands in both groups were Ashkenazi Jewish.

\section{Application of models}

The applicability of each model is summarized in Table 1. The BRCAPRO, Myriad II, FHAT and BOADICEA models were applied to all 300 probands. The Penn II model was used for all except 3 individuals from families with ovarian cancer only and no breast cancer. The Manchester model was applied to 181 non-Ashkenazi Jewish individuals. The Couch model was applied to all except 6 probands from families with only ovarian cancer or male breast cancer. The IBIS model was applicable to 65 female probands with no prior diagnosis of breast cancer. All models except the Myriad II, FHAT and Couch provided separate scores for BRCA1 and BRCA2, which were added to obtain a total BRCA score. Myriad II and FHAT provide only a total BRCA score. The Couch model calculates only BRCA1 probabilities.

\section{Ease of use}

For each model, ease of use was judged on the basis of the data required and the time used for data entry. The BRCAPRO, Couch, Myriad II and FHAT were calculated using CaGene 4.3 software, which requires the entire pedigree to be entered. However, the Couch, FHAT and Myriad II models can also be used via searchable tables of probabilities, with the tables for Myriad II developed for both Ashkenazi Jewish and non-Ashkenazi Jewish individuals. The Manchester model uses a scoring system. The IBIS and the Penn II models both use a one-page questionnaire requiring data on affected individuals only. As an example, the time taken by an experienced counsellor to enter the same 3 generation pedigree into each program was calculated. Data entry for BRCAPRO, Myriad II, Couch and FHAT (using CaGene 4.3 software) took 4 minutes. Data entry was 40 seconds for the Manchester model, $35 \mathrm{sec}$ onds for the Penn II model, 70 seconds for the IBIS model and 6 minutes for the BOADICEA model. The methods of data entry are summarized in Table 1.

\section{Measures of performance}

The ROC curves for BRCA status for all the models are shown in Figure 1. The AUCs are shown in Table 4 with 95\% confidence intervals. The BRCAPRO, Penn II, Myriad II, FHAT and BOADICEA models all have similar AUCs of approximately 0.75 for BRCA status, indicating that these models have similar discriminating power. The Manchester and IBIS models have lower AUCs (0.68 and 0.47). As expected, low risk patients have lower AUCs than high risk patients. Table 4 also demonstrates that the discriminating power is higher when only BRCA1 status is considered. All the models have low discriminating power for BRCA2. Table 5 shows the sensitivity and specificity for BRCA status at the conventional testing thresholds. In the full sample, and for the low risk subset, sensitivities at these conventional testing thresholds are $70 \%$ or lower for all models except the Penn II model, which exceeds 90\% sensitivity. Table 6 demonstrates that when appropriate thresholds are used, other models can also achieve 90\% sensitivity. At 90\% sensitivity, Penn II and Myriad II had the highest specificity in the full sample (approximately 35\%).

The following AUCs were obtained for the Ashkenazi Jewish and non-Ashkenazi Jewish subsets respectively: BRCAPRO (0.77; 0.76), Penn II (0.79; 0.72), Myriad II (0.74; $0.77)$, FHAT $(0.75 ; 0.74)$ and BOADICEA $(0.74 ; 0.74)$. The Manchester model has an AUC of 0.68 for the nonAshkenazi Jewish subset; it does not apply to Ashkenazi Jewish individuals.

\section{Discussion}

Combined with a detailed assessment by a genetic counsellor or geneticist, a complete risk assessment using vali-

Table 3: Characteristics of study population

\begin{tabular}{|c|c|c|}
\hline & $\begin{array}{l}\text { Carriers } \\
(n=100)\end{array}$ & $\begin{array}{c}\text { Non-Carriers } \\
(n=200)\end{array}$ \\
\hline \multirow[t]{2}{*}{ Carrier status } & BRCAI: $58 \%$ & not \\
\hline & BRCA2: $42 \%$ & applicable \\
\hline \multirow[t]{2}{*}{ Gender } & Female: $91 \%$ & Female: $\mathbf{9 8 \%}$ \\
\hline & Male: $9 \%$ & Male: $2 \%$ \\
\hline \multirow[t]{2}{*}{ Ashkenazi Jewish descent } & Yes: $39 \%$ & Yes: $40 \%$ \\
\hline & No: $61 \%$ & No: $60 \%$ \\
\hline Mean age ( \pm standard deviation) & $\begin{array}{l}51 \text { years } \\
( \pm 12.7)\end{array}$ & $\begin{array}{l}52 \text { years } \\
( \pm 13.5)\end{array}$ \\
\hline \multirow[t]{4}{*}{ Type of cancer } & Breast: $75 \%$ & Breast: $73 \%$ \\
\hline & Ovarian: $6 \%$ & Ovarian: $0 \%$ \\
\hline & Both: $4 \%$ & Both: $0 \%$ \\
\hline & Not affected: $15 \%$ & Not affected: $27 \%$ \\
\hline \multirow[t]{2}{*}{ Number of Ist degree relatives with breast or ovarian cancer } & None: $35 \%$ & None: $36 \%$ \\
\hline & One or more: $65 \%$ & One or more: $64 \%$ \\
\hline
\end{tabular}




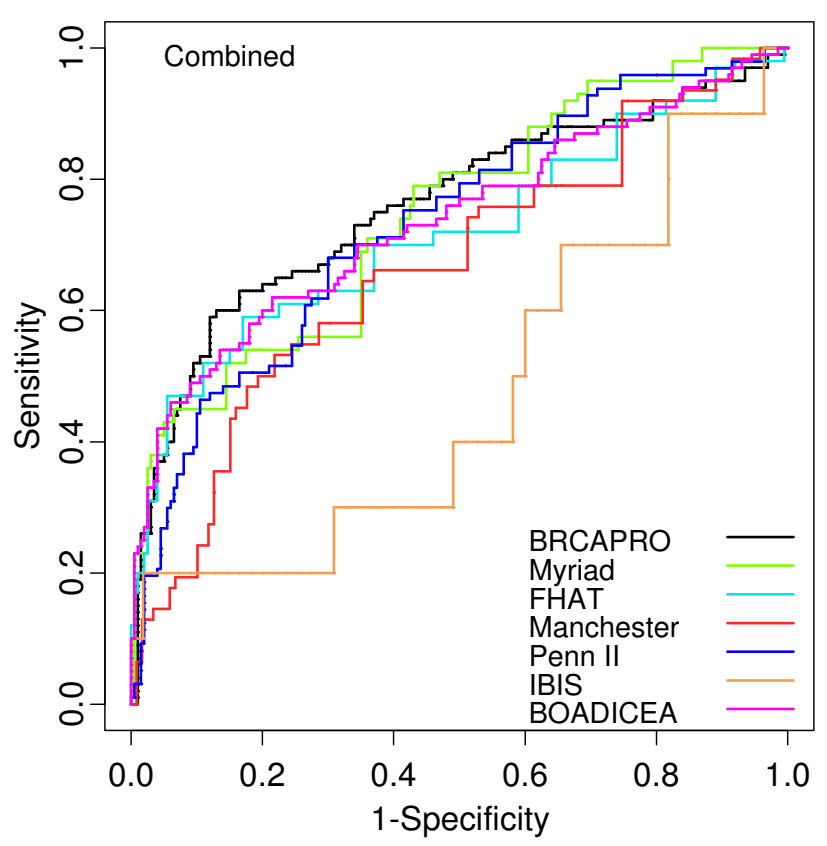

Figure I

Receiver operator characteristic (ROC) curves for risk assessment models for BRCAI and BRCA2 combined.

dated models helps to confront the challenge of identifying the greatest number of carriers while maximizing the use of limited healthcare funding for genetic testing in both privately and publicly funded healthcare systems.

\section{Application of models}

The IBIS model (which can only be used for unaffected probands) is of limited use in familial clinics where many of the individuals undergoing genetic testing have had breast cancer. Since our clinic has a relatively high proportion of Ashkenazi Jewish individuals, the Manchester model is of limited utility.

\section{Ease of use}

It was the experience of the counsellor performing risk assessments that the models requiring complete pedigree data entry took the longest time to complete, and those requiring a one-page questionnaire, a searchable table of probabilities or a scoring system took the least time. On this basis, the BRCAPRO and BOADICEA models required the most time for data entry. These two models also required information on the cancer status and age or age at death of all family members. These data were often difficult for probands to recall, and this possibly compromised the accuracy of the risk assessment. Models using a one page questionnaire (Penn II, IBIS), and those with a scoring system (Manchester) or table review (Myriad II) took the least time to complete. This is because these models required limited data on only those family members affected by cancer. Often these data were easier for probands to recall, thus probably decreasing inaccuracies in calculation.

\section{Testing thresholds}

Early publications have advocated the use of a 10\% testing threshold, and risk assessment models have been developed and validated around this. Our results clearly demonstrate that the widespread use of $10 \%$ is not appropriate for all models, clinics or purposes. Only one model (Penn II) was able to achieve a high sensitivity (90\%) consistently in our population using this conventional testing threshold. However, the Myriad II had similar sensitivity and specificity to the Penn II when a threshold of 5.8 was employed.

\section{Evaluation against criteria}

Prior to comparing the models, we developed criteria by which to assess them. At the recommended testing threshold of $10 \%$, the Penn II model achieved the highest sensitivity in comparison to all other models. The BRCAPRO, Myriad II, FHAT, Penn II and BOADICEA models were applicable to most probands. When the same model is used on all probands, this provides a consistent method of risk assessment. The least time-consuming models and the easiest for data entry and collection were the Penn II, IBIS, Myriad II and Manchester. All except the Couch model provided combined BRCA scores. Mainly on the basis of the sensitivity at the recommended testing threshold, but also taking account of wide applicability and ease of data collection and data entry, we conclude that the Penn II model is best suited for use in our clinic population.

\section{Biases}

Multiple methods of genetic testing for BRCA1 and BRCA2 mutations are available. In this study, protein truncation testing (PTT) was the methodology used. This method has a slightly lower sensitivity in finding BRCA1 and BRCA2 mutations than direct DNA sequencing $[16,34]$. Additionally, large gene rearrangements are not detected by PTT. Other testing techniques such as DHPLC combined with MLPA are more sensitive and can detect large gene rearrangements. However, they are also found to identify a greater number of variants of uncertain significance (VUS). Counseling and management of individuals with VUS remains a clinical challenge.

In a previous study based on a convenience sample of 103 unselected probands from our clinic [25], we also showed that the proportion of probands meeting the testing threshold varied by risk model: BRCAPRO (34\%), Myriad II (33\%), Manchester (55.3\%) and Penn II (46.6\%). The 
Table 4: Area under the receiver operating characteristic (ROC) curve with $95 \%$ confidence limits

\begin{tabular}{|c|c|c|c|}
\hline \multirow[t]{2}{*}{ Model } & \multicolumn{3}{|c|}{ Area under the ROC curve ( $95 \%$ confidence limits) } \\
\hline & All & Low risk subset & High risk subset \\
\hline \multicolumn{4}{|l|}{ BRCA status } \\
\hline BRCAPRO & $0.76(0.70-0.82)$ & $0.70(0.57-0.81)$ & $0.80(0.73-0.87)$ \\
\hline Manchester & $0.68(0.60-0.76)$ & $0.57(0.37-0.72)$ & $0.73(0.63-0.81)$ \\
\hline Penn II & $0.74(0.67-0.80)$ & $0.68(0.54-0.79)$ & $0.77(0.70-0.83)$ \\
\hline Myriad II & $0.76(0.7 I-0.82)$ & $0.70(0.59-0.80)$ & $0.80(0.72-0.86)$ \\
\hline FHAT & $0.74(0.66-0.80)$ & $0.66(0.55-0.76)$ & $0.83(0.76-0.89)$ \\
\hline IBIS & $0.47(0.28-0.69)$ & - & - \\
\hline BOADICEA & $0.74(0.67-0.80)$ & $0.68(0.56-0.79)$ & $0.77(0.70-0.84)$ \\
\hline \multicolumn{4}{|l|}{ BRCAI status } \\
\hline BRCAPRO & $0.80(0.72-0.87)$ & $0.8(0.62-0.91)$ & $0.8 \mathrm{I}(0.7 \mathrm{I}-0.88)$ \\
\hline Manchester & $0.78(0.69-0.86)$ & $0.74(0.46-0.93)$ & $0.79(0.69-0.88)$ \\
\hline Penn II & $0.79(0.72-0.85)$ & $0.76(0.61-0.86)$ & $0.81(0.73-0.87)$ \\
\hline COUCH & $0.82(0.75-0.87)$ & $0.82(0.65-0.92)$ & $0.84(0.75-0.89)$ \\
\hline IBIS & $0.43(0.28-0.56)$ & - & - \\
\hline BOADICEA & $0.80(0.72-0.86)$ & $0.79(0.61-0.89)$ & $0.80(0.7 \mathrm{I}-0.87)$ \\
\hline \multicolumn{4}{|l|}{ BRCA2 status } \\
\hline BRCAPRO & $0.60(0.50-0.68)$ & $0.57(0.42-0.7 I)$ & $0.62(0.48-0.73)$ \\
\hline Manchester & $0.60(0.49-0.70)$ & $0.56(0.34-0.74)$ & $0.63(0.49-0.74)$ \\
\hline Penn II & $0.57(0.48-0.65)$ & $0.54(0.39-0.69)$ & $0.58(0.46-0.69)$ \\
\hline IBIS & $0.58(0.29-0.84)$ & - & - \\
\hline BOADICEA & $0.63(0.54-0.73)$ & $0.59(0.4 I-0.76)$ & $0.67(0.55-0.77)$ \\
\hline
\end{tabular}

overall cost of BRCA genetic testing may ultimately be affected by the risk model used to determine eligibility.

Although the ROC curve and related statistics are not affected by mutation prevalence, we anticipated that our results may suffer from biases related to the characteristics of the probands in the case-control sample. The possibility of a selection bias exists because this case-control sample included only probands who completed BRCA genetic testing. This selection and the case-control sample structure can both result in 'spectrum of disease' bias. The 'spectrum of disease' refers to how obvious or hidden the condition to be detected is among the individuals in the sample. For the purposes of this study, the 'spectrum of disease' is used to describe the spectrum of risk of having a BRCA gene mutation. For example, sensitivity will be artificially high if one's sample has more probands with a strong family history of breast and ovarian cancer than the target population. We characterized the 'spectrum of disease' by the percentage of probands with none versus one or more first degree relatives with breast or ovarian cancer, and found that the results differed substantially for these two groups (Table 4). To address the possible bias of our case-control sample, we compared the proportion of high-risk and low-risk probands from this study to an unselected population using a tally of all patients referred to our clinic between May and October 2005. Out of 103 unselected probands referred during this time period,

Table 5: Sensitivity and specificity at the conventional thresholds

\begin{tabular}{|c|c|c|c|c|c|c|c|}
\hline \multirow[t]{2}{*}{ Model } & \multirow[t]{2}{*}{ Conventional threshold } & \multicolumn{3}{|c|}{ Sensitivity at conventional threshold } & \multicolumn{3}{|c|}{ Specificity at conventional threshold } \\
\hline & & All & Low risk subset & High risk subset & All & Low risk subset & High risk subset \\
\hline \multicolumn{8}{|l|}{ BRCA status } \\
\hline BRCAPRO & 10 & 0.75 & 0.63 & 0.82 & 0.62 & 0.70 & 0.58 \\
\hline Manchester & 15 & 0.58 & 0.39 & 0.64 & 0.71 & 0.73 & 0.72 \\
\hline Penn II & 10 & 0.93 & 0.94 & 0.92 & 0.31 & 0.14 & 0.40 \\
\hline Myriad II & 10 & 0.71 & 0.66 & 0.74 & 0.63 & 0.65 & 0.62 \\
\hline FHAT & 10 & 0.70 & 0.34 & 0.89 & 0.63 & 0.85 & 0.51 \\
\hline IBIS & 10 & 0.20 & - & - & 0.74 & - & - \\
\hline BOADICEA & 10 & 0.70 & 0.63 & 0.74 & 0.65 & 0.70 & 0.62 \\
\hline
\end{tabular}


Table 6: Threshold to obtain $90 \%$ sensitivity and corresponding specificity

\begin{tabular}{|c|c|c|c|c|c|c|}
\hline \multirow[t]{2}{*}{ Model } & \multicolumn{3}{|c|}{ Threshold to obtain $\mathbf{9 0 \%}$ sensitivity } & \multicolumn{3}{|c|}{ Specificity at $\mathbf{9 0 \%}$ sensitivity } \\
\hline & All & Low risk subset & High risk subset & All & Low risk subset & High risk subset \\
\hline \multicolumn{7}{|l|}{ BRCA status } \\
\hline BRCAPRO & 1.97 & 0.47 & 4.20 & 0.21 & 0.06 & 0.39 \\
\hline Manchester & 7.58 & 7.60 & 7.10 & 0.27 & 0.17 & 0.31 \\
\hline Penn II & 10.90 & 10.65 & 11.20 & 0.35 & 0.18 & 0.45 \\
\hline Myriad II & 5.80 & 6.20 & 5.75 & 0.36 & 0.27 & 0.40 \\
\hline FHAT & 6.00 & 4.10 & 8.83 & 0.26 & 0.26 & 0.38 \\
\hline IBIS & 0.26 & - & - & 0.18 & - & - \\
\hline BOADICEA & 2.77 & 1.94 & 3.08 & 0.22 & 0.11 & 0.25 \\
\hline
\end{tabular}

there was a prevalence of 33\% low risk probands (no first degree relatives with breast/ovarian cancer). In the full case-control sample used in this study, we had a similar percentage of low-risk probands (35\%). This suggests that the risk assessment models would perform similarly in this case-control sample and an unselected sample.

We also investigated the effect of having a sample with a fairly high proportion of Ashkenazi Jewish probands. The presence of Ashkenazi Jewish probands did not affect the AUCs greatly. Using knowledge of their own case mix and judiciously weighing the results, other genetics clinics can adapt our results to their populations.

These study results are applicable to a familial genetics program where probands have a personal and/or family history of cancer, but may not be useful for the general population. A further limitation of the study is that the sample size was optimized for the full case-control sample. Thus the estimates obtained from the subset analyses are less precise.

\section{Conclusion}

A number of factors should be considered when deciding on the risk assessment models to use in a familial genetics program. The model should have very high sensitivity, data should be easy to obtain, data entry should be fast and efficient, and the model should be applicable to most patients regardless of cancer status, sex, or degree of cancer history within the family. In our clinic, the Penn II model came closest to meeting the above criteria in comparison to other risk assessment models when the recommended testing threshold was used.

In our study, we compared all available models, including BRCAPRO, the newly updated (2007) version of the Penn II model, and the BOADICEA model that recently became publicly accessible. We demonstrated that conventional thresholds may not be appropriate for all models and purposes, and this aspect deserves further study. Providing information on the spectrum of patients we studied and giving results separately for low and high risk patients allow other clinics to apply these results to their patient populations.

\section{Competing interests}

The authors declare that they have no competing interests.

\section{Authors' contributions}

SP contributed to the study design, collected data and obtained access to all risk assessment models, and drafted the first version of the manuscript. ME performed the statistical analysis and developed the statistical content of the manuscript. SC performed the data collection and applied patient data to calculate risks using the assessment models. LB oversaw the conception and design of the study, data analysis and interpretation, and significantly contributed to the revisions of the intellectual content of the manuscript. All authors read and approved the final manuscript.

\section{Acknowledgements}

We would like to thank the Marvelle Koffler Breast Centre and the Clinical Trials and Research Program at Mount Sinai Hospital in Toronto, Canada for their ongoing support. No source of funding was used for this study.

\section{References}

I. Canadian Cancer Society/National Cancer Institute of Canada: Canadian Cancer Statistics 2007.

2. Hall JM, Lee MK, Newman B, Morrow JE, Anderson LA, Huey B, et al.: Linkage of early-onset familial breast cancer to chromosome I7q2 I I. Science 1990, 250: |684-1689.

3. Wooster R, Neuhausen SL, Mangion J, Quirk Y, Ford D, Collins N, et al.: Localization of a breast cancer susceptibility gene, BRCA2, to chromosome I3q I 2-I3. Science I994, 265:2088-2090.

4. Garber JE, Goldstein AM, Kantor AF, Dreyfus MG, Fraumeni JF Jr, Li FP: Follow-up study of twenty-four families with Li-Fraumeni syndrome. Cancer Res 1991, 51:6094-6097.

5. Tsou HC, Teng DH, Ping XL, Brancolini V, Davis T, Hu R, et al.: The role of MMACI mutations in early-onset breast cancer: causative in association with Cowden syndrome and excluded in BRCA I -negative cases. Am J Hum Genet 1997, 6 I: I036-I043.

6. Thompson D, Duedal S, Kirner J, McGuffog L, Last J, Reiman A, et al.: Cancer risks and mortality in heterozygous ATM mutation carriers. J Natl Cancer Inst 2005, 97:813-822.

7. Thompson D, Easton D: The genetic epidemiology of breast cancer genes. J Mammary Gland Biol Neoplasia 2004, 9:221-236. 
8. Chen S, Iversen ES, Friebel T, Finkelstein D, Weber BL, Eisen A, et al.: Characterization of BRCAI and BRCA2 mutations in a large United States sample. J Clin Oncol 2006, 24:863-87I.

9. Srivastava A, McKinnon W, Wood ME: Risk of breast and ovarian cancer in women with strong family histories. Oncology (Williston Park) 200I, I 5:889-902.

10. Risch HA, McLaughlin JR, Cole DE, Rosen B, Bradley L, Kwan E, et al: Prevalence and penetrance of germline BRCAI and BRCA2 mutations in a population series of 649 women with ovarian cancer. Am J Hum Genet 200I, 68:700-7I0.

II. Easton DF, Steele L, Fields P, Ormiston W, Averill D, Daly PA, et al: Cancer risks in two large breast cancer families linked to BRCA2 on chromosome I3qI2-I3. Am J Hum Genet 1997, 6 I: $120-128$.

12. Cancer risks in BRCA2 mutation carriers. The Breast Cancer Linkage Consortium. J Natl Cancer Inst 1999, 91: I3 10-13 I6.

13. Myriad Genetic Laboratories Inc SLCU: BRACAnalysis 2008.

14. Gross E, Arnold N, Pfeifer K, Bandick K, Kiechle M: Identification of specific BRCAI and BRCA2 variants by DHPLC. Hum Mutat 2000, I 6:345-353.

15. den Dunnen JT, Roest PA, Luijt RA Van Der: The protien truncation testing (PTT) for rapid detection of translating-terminating mutations. New York, Plenum Press; 1996:323-34l.

16. Andrulis IL, nton-Culver H, Beck J, Bove B, Boyd J, Buys S, et al.: Comparison of DNA- and RNA-based methods for detection of truncating BRCAI mutations. Hum Mutat 2002, 20:65-73.

17. Palma M, Ristori E, Ricevuto E, Giannini G, Gulino A: BRCAI and BRCA2: the genetic testing and the current management options for mutation carriers. Crit Rev Oncol Hematol 2006, 57:1-23.

18. Berry DA, Iversen ES Jr, Gudbjartsson DF, Hiller EH, Garber JE, Peshkin BN, et al:: BRCAPRO validation, sensitivity of genetic testing of BRCAI/BRCA2, and prevalence of other breast cancer susceptibility genes. J Clin Oncol 2002, 20:270 I-27I2.

19. Parmigiani G, Berry D, Aguilar O: Determining carrier probabilities for breast cancer-susceptibility genes BRCAI and BRCA2. Am J Hum Genet 1998, 62:145-158.

20. Berry DA, Parmigiani G, Sanchez J, Schildkraut J, Winer E: Probability of carrying a mutation of breast-ovarian cancer gene BRCAI based on family history I I. J Natl Cancer Inst 1997. 89:227-238.

21. Frank TS, Deffenbaugh AM, Reid JE, Hulick M, Ward BE, Lingenfelter $B$, et al.: Clinical characteristics of individuals with germline mutations in BRCAI and BRCA2: analysis of 10,000 individuals. I Clin Oncol 2002, 20: |480-| 490.

22. Couch FJ, DeShano ML, Blackwood MA, Calzone K, Stopfer J, Campeau $\mathrm{L}$, et al.: BRCAI mutations in women attending clinics that evaluate the risk of breast cancer. N Engl J Med 1997, 336: |409-|4|5.

23. Gilpin CA, Carson N, Hunter AG: A preliminary validation of a family history assessment form to select women at risk for breast or ovarian cancer for referral to a genetics center. Clin Genet 2000, 58:299-308.

24. Evans DG, Eccles DM, Rahman N, Young K, Bulman M, Amir E, et al: A new scoring system for the chances of identifying a BRCA II 2 mutation outperforms existing models including BRCAPRO. J Med Genet 2004, 4 I:474-480.

25. The Penn II BRCAI and BRCA2 mutation risk evaluation model. 2008.

26. Tyrer J, Duffy SW, Cuzick J: A breast cancer prediction model incorporating familial and personal risk factors. Stat Med 2004, 23: IIII-II30.

27. Antoniou AC, Pharoah PP, Smith P, Easton DF: The BOADICEA model of genetic susceptibility to breast and ovarian cancer. $\mathrm{Br}$ J Cancer 2004, 9 I: I580- I 590.

28. Antoniou AC, Pharoah PD, McMullan G, Day NE, Stratton MR, Peto , et al:: A comprehensive model for familial breast cancer incorporating BRCAI, BRCA2 and other genes. $\mathrm{Br} J$ Cancer 2002, 86:76-83.

29. Hintz J: NCSS and PASS, Number Cruncher Statistical Systems. Kaysville, Utah; $200 \mathrm{I}$.

30. Euhus DM, Berry D, Parmigiani G, Iversen ES, Frawley W: CaGene. [4.3]. U.T. Southwestern Medical Centre at Dallas; 2006.

31. BOADICEA: Department of Public Health and Primary Care; 2007.

32. Zhou X, Obuchowski N, McClish D: Statistical Methods in Diagnostic Medicine New York: John Wiley \& Sons, Inc; 2002.
33. Carpenter J, Bithell J: Bootstrap confidence intervals: when, which, what? A practical guide for medical statisticians. Stat Med 2000, I9: I 14I-1 I64.

34. Garvin AM: A complete protein truncation test for BRCAI and BRCA2. Eur J Hum Genet 1998, 6:226-234.

\section{Pre-publication history}

The pre-publication history for this paper can be accessed here:

http://www.biomedcentral.com/1471-2350/9/116/pre pub
Publish with BioMed Central and every scientist can read your work free of charge

"BioMed Central will be the most significant development for disseminating the results of biomedical research in our lifetime. "

Sir Paul Nurse, Cancer Research UK

Your research papers will be:

- available free of charge to the entire biomedical community

- peer reviewed and published immediately upon acceptance

- cited in PubMed and archived on PubMed Central

- yours - you keep the copyright 